\title{
DIMENSÕES DA COOPERAÇÃO JURÍDICA INTERNACIONAL: DO DIREITO À COOPERAÇÃO AO DEVER DE COOPERAR
}

\author{
DIMENSIONS OF INTERNATIONAL JUDICIAL COOPERATION: FROM THE RIGHT \\ OF COOPERATION TO THE DUTY TO COOPERATE
}

Camilla Capucio* $^{*}$

\begin{abstract}
RESUMO
Diante da intensificação do fluxo de pessoas e das atividades humanas, que ultrapassam as fronteiras permeáveis dos Estados, fica clara a insuficiência do império da jurisdição estatal e a necessidade do desenvolvimento de um novo paradigma para compreensão da relação entre os Estados e os sujeitos, atos e pleitos sob sua jurisdição. A cooperação jurídica internacional, em seus diversos instrumentos, está no centro deste novo paradigma, em um contexto de reinterpretação da soberania e da jurisdição estatal, e rumo à justiça universal como um valor internacional. Assim, este trabalho busca analisar as distintas dimensões da cooperação jurídica internacional, com enfoque especial na reflexão sobre a existência de um direito de cooperação e um dever de cooperar, sob a perspectiva da concretização dos direitos humanos dos sujeitos envolvidos. Partindo-se desse intuito, é feita uma análise sistemática por meio da doutrina e da jurisprudência internacional na temática.
\end{abstract}

\section{PALAVRAS-CHAVE}

Cooperação jurídica internacional. Direito à cooperação. Dever de cooperar. Princípio da justiça universal. Direitos humanos.

\begin{abstract}
Given the intense flow of people and human activities that transit beyond the porous borders of States, there is a clear failure of the State jurisdiction empire and an urgent need to develop a new paradigm for understanding the relationship between the States and the subject, acts and claims under their jurisdiction. International judicial cooperation, in its various instruments, is at the heart of this new paradigm, in a context of reinterpretation of sovereignty and jurisdiction, and towards the universal jurisdiction as an international value. This paper analyzes the different dimensions of international judicial cooperation, with special focus on the reflection about the existence of a right of cooperation and a duty to cooperate, in the light of materializing human rights of persons involved. With this intent, the paper is developed through a systemic analysis of doctrine and international jurisprudence in this regard.
\end{abstract}

\section{KEYWORDS}

International judicial cooperation. Right of cooperation. Duty to cooperate. Principle of universal justice. Human rights.

\footnotetext{
* Doutora em Direito Internacional pela Faculdade de Direito da USP. Mestre e graduada em Direito pela Faculdade de Direito da UFMG. Professora convidada em cursos de pós-graduação lato sensu. Pesquisadora no Núcleo de Estudos em Tribunais Internacionais (NETI-USP). Coordenadora e pesquisadora no grupo de pesquisa Empresa, Mercado e Desenvolvimento Social e professora (Centro Universitário Una). Membro da Academia Brasileira de Direito Internacional (ABDI) e da Sociedade Latino-Americana de Direito Internacional (SLADI). Associada honorária do Instituto de Comércio Internacional do Brasil (ICI-BR). Advogada (São Paulo, SP, Brasil). E-mail: ccapucio@usp.br
} 
SUMÁRIO: 1 Ponto de partida: necessidade de nova interpretação da jurisdição estatal. 2 Da cooperação jurídica internacional. 2.1 As vias, os fundamentos e os paradigmas da cooperação. 2.2 Os institutos da cooperação: entre os agentes e os sujeitos da cooperação. 2.3 O princípio da justiça universal 3 Do direito à cooperação jurídica internacional 3.1 O direito à cooperação jurídica sob a ótica da vítima $3.2 \mathrm{O}$ direito à cooperação jurídica sob a ótica do acusado/condenado. 4 Do dever de cooperação dos Estados 4.1 A existência de um dever geral de cooperação. 4.2 A exigência da não cooperação. 5 Considerações finais. Referências.

\section{PONTO DE PARTIDA: NECESSIDADE DE NOVA INTERPRETAÇÃO DA JURISDIÇÃO ESTATAL}

Jurisdição pode ser entendida, em seu conceito clássico, como a descrição dos limites da competência legal de um Estado para formular, aplicar e executar regras e condutas relativas às pessoas. Refere-se, assim, à extensão do direito de cada Estado de regular condutas ou as consequências de eventos (LOWE, 2006, p. 329-355). Esse conceito tem sido estudado de maneira intrinsecamente conectada à ideia de soberania, sendo inclusive entendido como um aspecto desta, devido principalmente à matriz territorial que de início vincularia e limitaria ambas as noções (BROWNLIE, 2003, p. 297-298).

Com a evolução das sociedades e das relações entre os povos para além de suas fronteiras, contudo, restou explícita a insuficiência dessa compreensão da soberania, em face da nova realidade fática que se apresenta, em especial nas últimas décadas. Isso pois os indivíduos, os interesses, as relações jurídicas, os atos ilícitos e suas consequências na atualidade se situam em ambiente crescentemente transnacional e internacional, exigindo uma nova formulação desses conceitos, capaz de lidar com as novas complexidades.

Diante da insuficiência do império da jurisdição estatal, baseada quase que exclusivamente na territorialidade, o direito internacional contemporâneo tem se desenvolvido nesta seara de modo a fornecer respostas às profundas modificações apresentadas pela realidade da qual se origina e a qual objetiva normatizar (MENEZES, 2005). Como principais desenvolvimentos, podemos elencar a evolução e adensamento jurídico da cooperação jurídica internacional, em seus diversos institutos, e a valorização do princípio da jurisdição universal.

No plano doutrinário, esses desenvolvimentos são refletidos na busca por uma reinterpretação do conceito de soberania, ao qual se vincula o de jurisdição. É o caso de Anne-Marie Slaughter, que enfatiza a imperatividade dessa reinterpretação, uma vez que a soberania westfaliana, ligada ao território do Estado e à sua capacidade de atuar internacionalmente como agente autônomo, enfrenta dois desafios hodiernamente: a inefetividade da ação individual e a existência de interferências nessa soberania (SLAUGHTER, 2004). Assim, exige-se uma nova interpretação da 
soberania, relacionada à capacidade de participação em regimes internacionais e transgovernamentais, redes e instituições agora necessárias para o alcance de objetivos na sociedade internacional. A nova soberania se relaciona, portanto, à capacidade de participar em esforços conjuntos, e estar em conexão com o resto do mundo. Não se trata de transferência ou diluição da soberania estatal, mas sim uma recaracterização de uma soberania como controle para uma soberania como responsabilidade, em funções internas e deveres externos.

A transformação observada no conceito de soberania, portanto, é resposta às transformações no sistema internacional e nas relações internacionais no século XX, que abrem espaço para a atuação das instituições internacionais como forma de reafirmar (esse novo tipo de) soberania. Um exemplo claro desse novo cenário é a formação de redes de governança, em resposta a ameaças que também seguem uma lógica crescentemente retificada. Trata-se, pois, de uma soberania relacional, de modo a preservar com efetividade o sentido que nunca perdeu, de direito-dever do Estado de prover e proteger seu povo (SLAUGHTER, 2004, p. 283-327).

A soberania relacional é, pois, o contexto ideal para a cooperação entre os Estados, e entre os Estados e as organizações internacionais, com diversos fins, entre eles o compartilhamento do aparato estatal para a resolução de questões jurídicas. A cooperação, de maneira geral, pode ser visualizada como um princípio basilar de um novo modelo internacional, fundado ainda no princípio de solidariedade. Resta adentrar um pouco mais nos institutos da cooperação jurídica internacional, com o intuito posterior de avaliar a existência de um eventual direito à cooperação de titularidade dos indivíduos e um eventual dever de cooperação por parte dos Estados.

A partir desta - breve, mas necessária - recontextualização do significado de soberania, o presente trabalho buscará problematizar a cooperação jurídica internacional sob as dimensões dos deveres e dos direitos na ordem jurídica internacional. Partindo-se de um novo paradigma que se distancia de uma visão soberanista, para aproximar-se de uma perspectiva comunitarista da ordem jurídica internacional, as demais seções do trabalho discutirão, respectivamente: (a) a cooperação jurídica internacional, como objeto de estudo sistematizado; (b) a justiça universal, compreendida como um valor fundante de uma nova ordem cooperativa, (c) o direito de cooperação, sob diferentes pontos de vista, e (d) o dever de cooperação, fundado no respeito aos direitos humanos e que pode inclusive ser invertido, buscando-se a concretização última da proteção a esses direitos mínimos.

\section{DA COOPERAÇÃO JURÍDICA INTERNACIONAL}

Cooperação jurídica internacional ou, como preferem alguns, assistência jurídica 
internacional (PETRUS, 2005, p. 27-69) deve ser modernamente conceituada como um conjunto de procedimentos e princípios por meio dos quais um Estado presta auxílio a outro Estado ou a uma organização internacional, em relação a uma atuação processual concreta que deve desenrolar-se no território do primeiro, contribuindo para uma solução final no sistema jurisdicional do último.

A definição que trazemos abarca os seguintes elementos, que explicitam tendências da matéria que não devem ser ignoradas: (a) a existência, ou ao menos a busca, de princípios e procedimentos que sistematizem a disciplina; (b) a participação crescente de organizações internacionais como agentes da cooperação jurídica internacional; (c) a perspectiva da cooperação jurídica internacional como uma grande área, dentro da qual estão incluídas diferentes espécies.

No que tange ao último elemento, é importante destacar, pois, que a cooperação jurídica internacional pode ser subdividida em cooperação jurídica penal internacional e cooperação jurídica civil internacional, segundo a natureza jurídica do ato processual em questão. A diferenciação é relevante para fins de visualização dos principais bens jurídicos e direitos envolvidos, que podem vir a influenciar no sopesamento a ser feito pelos agentes envolvidos. Outra classificação pode ser feita de acordo com os agentes que participam da cooperação, sendo horizontal quando envolve apenas Estados, ou vertical quando envolve organizações internacionais.

Inseridos na cooperação jurídica internacional em sentido lato estão diversos pleitos cooperacionais, entre os quais se salienta, em enumeração não exaustiva: (a) reconhecimento/execução de decisões estrangeiras cíveis; (b) pedidos relacionados ao direito de família; (c) pedidos de instrução penal; (c) pedidos para concretização de medidas de busca e apreensão, ou indisponibilidade de bens; (d) a extradição; (d) a entrega de indivíduos para o julgamento por tribunais internacionais; (e) a transferência de sentenciados (ARAS, 2010).

A assistência jurídica, a carta rogatória, a homologação de sentença estrangeira e o auxílio direto $^{1}$ são as modalidades para o trânsito desses pleitos no sistema jurídico-administrativo do Estado requerido, podendo ter como objeto esses e outros pedidos, que não encontram previsão taxativa.

\subsection{AS VIAS, OS FUNDAMENTOS E OS PARADIGMAS DA COOPERAÇÃO}

Com relação a essas diversas modalidades, tem se manifestado na sociedade internacional um movimento crescente de densificação e juridificação dos respectivos compromissos e

\footnotetext{
${ }^{1} \mathrm{O}$ auxílio direto constitui um elemento inovador na cooperação jurídica internacional no Brasil face aos outros três institutos classicamente previstos pelo ordenamento pátrio, e tem sido frequentemente utilizado para pleitos cooperacionais em matéria penal. Para o conceito, histórico, características e previsão normativa do instituto, cf. LOULA, 2010, p. 94-121.
} 
instrumentos. É o que apontam Kenneth Abbott e Duncan Snidal, em trabalho no qual se concentram em responder à questão de como os Estados e outros atores internacionais passam de um nível ou tipo de cooperação a outro, em processos de incrementação ou densificação da cooperação, que envolvem diferentes instrumentos, a exemplo de declarações não vinculantes, compromissos vagos e acordos plurilaterais mais específicos (ABBOTT; SNIDAL, 2004).

Os autores com clareza explicitam que os Estados com frequência não conseguem passar diretamente para uma solução cooperativa devido a problemas de informação, barganha e distribuição, e os processos diversos de incrementação cooperativa permitem, pois, que os Estados assumam compromissos que lhes sejam possíveis, diante de suas incertezas e possibilidades. Nesses processos de adensamento da cooperação, os autores identificaram três dimensões da cooperação: o conteúdo substantivo dos instrumentos, a participação dos agentes e a juridicidade dos preceitos contidos nos instrumentos.

Após a identificação de três tipos ideais de caminhos para a cooperação internacional, que trabalham de maneira isolada com a forma mais fraca de cada uma das dimensões respectivamente, como as vias da Convenção Quadro, dos Acordos Plurilaterais e da Soft Law (MENEZES, 2005, p. 140-172), concluem que, na realidade da sociedade internacional, os caminhos se mesclam e não são mutuamente exclusivos.

Se em uma perspectiva clássica a cooperação é vista como fruto exclusivo de uma cortesia entre os Estados - o comitas gentium - (OTAVIO, 1942, p. 115), é certo que hodiernamente os institutos da cooperação jurídica internacional encontram seu fundamento principal em instrumentos de diversas naturezas. Além do comitas gentium, que representa o soberanismo discricionário dos Estados, são apontados como fundamentos da cooperação jurídica internacional, sob o ponto de vista do Estado requerido: (a) tratados internacionais; (b) costume internacional; (c) interesse em reciprocidade; (d) benefício indireto a seus nacionais; (e) legislação interna e constituição (PETRUS, 2005, p. 27-69).

Acerca da existência de um costume internacional na matéria, a doutrina se divide. Parte entende que haveria um costume internacional de cooperação obrigatória a todos os Estados, derivado do princípio da solidariedade, ou princípio da comunidade jurídica, e na constatação do caráter fundamental do processo como instrumento para a solução de litígios. Outra parte da doutrina, contudo, acredita inexistir costume internacional, dada a ausência de seu elemento subjetivo, a opinio juris.

É certo que, diante da diversidade desses institutos e principalmente da diversidade com que têm sido interpretados pelos diferentes Estados e seus respectivos sistemas jurídicos, parece difícil 
reconhecer em todas as modalidades de cooperação ambos os requisitos para a comprovação de um costume internacional. Contudo, temos presente na sociedade internacional um dever geral de cooperação, derivado de princípios como a solidariedade internacional (MENEZES, 2007, p. 257266) e a universalidade da jurisdição, bem como da imperatividade de valores como a justiça, a verdade e os direitos humanos.

E, ainda, estamos diante de uma visível evolução dos institutos cooperativos, no que tange ao tratamento dado pelo direito internacional, à ampliação de suas fontes e ao papel dos sujeitos internacionais nesses pleitos.

Exatamente diante do caráter evolutivo da disciplina, André de Carvalho Ramos (2014) e Denise Neves Abade (2013, p. 59-63) propõem uma análise da cooperação jurídica internacional por meio de três paradigmas, que dizem respeito ao tratamento dado pelos países aos institutos da cooperação e explicitam matrizes de interpretação para as decisões dos Estados. São eles, em ordem de crescente disposição à cooperação: (a) paradigma da coexistência desigual; (b) paradigma da cooperação interessada e (c) paradigma da confiança.

O primeiro paradigma, da coexistência desigual, é marcado pelo soberanismo nas relações entre os Estados, que se traduz em uma cooperação tópica, desequilibrada, e feita por meio do filtro da pauta de valores do Estado requerido. A evolução deste ao próximo paradigma se dá com a proibição do uso da força na sociedade internacional, uma vez que o recurso legítimo à força coibiria a existência de estímulos e de necessidade de cooperação.

O segundo paradigma, da cooperação interessada, cujo marco é o Tratado de Versalhes, teria inaugurado a Era da Cooperação, que passa a se desenvolver entre Estados, situados no mesmo nível, extinto o elemento da subordinação. Diante do ambiente internacional favorável, as convenções pactuadas deram maior previsibilidade aos institutos, permitindo a existência de um verdadeiro ambiente cooperacional. Embora ainda seja possível a denegação do pleito cooperacional, sob a rubrica do interesse nacional, há a exigência de justificativa da denegação, o que por si só é avanço na juridicidade do tratamento. E, ainda, o regramento da cooperação recebe reforço devido a fatores internos, como a democracia na ordem interna, e a fatores externos, como a emergência dos direitos humanos, o que leva a disciplina a ser discutida e decidida por tribunais nacionais e internacionais.

O desenvolvimento dos laços cooperacionais, o adensamento de juridicidade de seus instrumentos e a consolidação de organizações internacionais do ambiente cooperacional tendem a levar ao terceiro paradigma, que embora não tenha alcançado todos os Estados, parece ser o destino para o qual se avança. O paradigma da confiança se traduz no reconhecimento mútuo de confiança entre os sistemas jurídicos nacionais, que supera as diferenças em elogio à crença nos mesmos valores 
jurídicos. Este paradigma tem se manifestado no contexto de experiências integracionistas notadamente a integração europeia - exatamente porque nesses processos a confiança mútua e a solidariedade são elemento essencial, e capazes de concretizar uma das motivações originárias da integração, qual seja, a eliminação de óbices entre Estados, entre eles a não cooperação.

Desse modo, no paradigma da confiança é vislumbrada determinada equivalência estrutural entre os sistemas jurídicos e os valores basilares dos Estados - o que não significa identidade. É cediço que a cooperação pressupõe, em certa medida, a desigualdade, pois é o que a torna necessária e relevante.

Por outro lado, o ambiente integracionista é o espaço para o estabelecimento de "pontes normativas” entre os sistemas jurídicos internos, e pode, mediante mecanismos de aproximação, harmonização e inclusive unificação, mitigar os obstáculos à construção de um espaço de livre circulação também de decisões jurídicas, provas, indiciados e condenados, etc. (MENEZES, 2005)

\title{
2.2 OS INSTITUTOS DA COOPERAÇÃO: ENTRE OS AGENTES E OS SUJEITOS DA COOPERAÇÃO
}

Diretamente inter-relacionada com o desenvolvimento dos institutos da cooperação e do avanço de um paradigma em direção ao próximo estágio está a evolução do próprio direito internacional como sistema, e a paulatina inclusão e valorização do indivíduo como sujeito de direitos e deveres na esfera internacional. O retorno ao jusnaturalismo - e, nesse sentido, do reconhecimento de direitos universalmente inerentes ao ser humano - em verdade é afirmação e consolidação do primado, na ordem dos valores, das obrigações estatais em matéria de direitos humanos, face à comunidade internacional como um todo, pois relativas a interesses comuns superiores.

Esta é ideia central das obras de Antônio Augusto Cançado Trindade:

\begin{abstract}
O ser humano passa a ocupar, em nossos dias, a posição central que lhe corresponde, como sujeito do direito tanto interno como internacional, em meio ao processo de humanização do Direito Internacional, o qual passa a se ocupar mais diretamente da identificação e realização de valores e metas comuns superiores. A titularidade jurídica internacional do ser humano é hoje uma realidade inegável, cabendo agora consolidar sua plena capacidade jurídica e processual no plano internacional. Temos todos o dever inescapável de dar nossa contribuição neste sentido, ainda mais por corresponder o reconhecimento da centralidade dos direitos humanos ao novo ethos de nosso tempo. O ser humano é, incontestavelmente, em última análise, o sujeito último do direito tanto interno como internacional (CANÇADO TRINDADE, 2008, p. 15)
\end{abstract}

A centralidade do indivíduo no direito internacional é elemento fundamental para as análises que se seguem. Isso pois partimos do pressuposto de que os institutos da cooperação devem ser estudados em um duplo contorno: (a) sob a perspectiva da relação entre os Estados, ou entre Estados 
e organizações internacionais, e (b) sob a perspectiva dos indivíduos juridicamente envolvidos da questão, que devem ter seus interesses e bens jurídicos sopesados.

Sobre ponto semelhante, ensina Nadia de Araujo:

[C]omo pano de fundo da Cooperação Jurídica Internacional está presente a questão do respeito aos direitos humanos e aos direitos fundamentais do indivíduo, ponto axial de todo o ordenamento jurídico brasileiro, especialmente depois da proeminência que lhe foi conferida pela Constituição Federal de 1988. Por isso, não pode faltar à discussão do tema um olhar sob dois prismas distintos que dizem respeito à perspectiva a ser adotada na hora de concretizar a cooperação internacional: de um lado, uma perspectiva ex parte principis, ou seja, a lógica do Estado preocupado com a governabilidade e com a manutenção de suas relações internacionais; de outro, a perspectiva ex parte populi, a dos que estão submetidos ao poder, e cuja preocupação é a liberdade, tendo como conquista os direitos humanos (ARAUJO, 2010, p. 2-3)

E vamos além, ao acreditarmos que nesse pano de fundo que não pode ser ignorado se incluem também os princípios e normas do direito internacional, explicitados em suas diferentes fontes e inegavelmente vinculantes aos Estados em todos os seus atos - internos ou internacionais. Assim, na decisão fática de um pleito cooperacional devem ser sopesados pelos Estados não somente os instrumentos nos quais se baseia o pedido entre os Estados, ou entre um Estado e uma organização internacional. Devem ser sopesados principalmente os direitos humanos dos indivíduos envolvidos na questão, direitos estes de observância obrigatória pelos Estados, sob pena de possível responsabilização internacional.

É certo, contudo, que o sopesamento dos direitos dos indivíduos envolvidos em um caso de cooperação pode levar a diferentes resultados concretos. Isto é, o resultado não será necessariamente a decisão de cooperar; em determinados casos a não cooperação poderá ser decisão que melhor resguarda os direitos humanos do indivíduo mais fragilizado na questão, e a cooperação, sem passar por uma análise efetiva dos bens jurídicos em jogo poderia, em tese, levar o Estado a uma responsabilidade secundária por seus atos. Passemos, pois, a uma breve noção do princípio da justiça universal, que permeia toda reflexão acerca da cooperação jurídica internacional.

\subsection{O PRINCÍPIO DA JUSTIÇA UNIVERSAL}

O conceito de jurisdição universal tem longa história, que pode ser traçada desde ao menos o Código Justiniano, no século XI, e foi reconhecido como um princípio aplicado a crimes no direito internacional a partir do trabalho de estudiosos da Idade Média, incluindo Francisco de Vitória no século XVI e Hugo Grócio no século XVII (ANISTIA INTERNACIONAL, 2001). Esses e outros estudiosos do então direito das gentes desenvolveram o princípio como correspondente à ideia de que certos tipos de crimes deveriam estar sujeitos à jurisdição de qualquer tribunal do mundo, 
independentemente de onde e por quem fossem cometidos (HAWKINS, 2003).

É notável o avanço da temática a partir das duas guerras mundiais, quando se iniciou a celebração de tratados internacionais que previam a jurisdição internacional. Principalmente nas últimas décadas, tem sido observada na sociedade internacional uma valorização e tentativa de concreção deste princípio, seja por meio da criação de tribunais internacionais com competência para julgar indivíduos por determinados crimes, seja mediante a criação de leis nacionais que conferem esse tipo de competência a seus tribunais internos.

Embora o também chamado princípio da universalidade da jurisdição seja evocado ainda hoje também para o julgamento e punição de atos cujo iter criminis tenha caráter espacialmente diferenciado, que impeça de outra forma sua punição, a exemplo da pirataria em alto-mar ou o sequestro de aviões (LOWE, 2006, p. 329-355), há uma tendência a conectá-lo cada vez mais aos direitos humanos e à noção de justiça internacional.

Este último aspecto é o que explica a retomada desse princípio, muitos séculos depois de sua formulação doutrinária, em um contexto de judicialização internacional dos direitos humanos, e de forma a superar alguns dos desafios da aplicação e concretização desses direitos (PIOVESAN, 2010). O que justifica o princípio, sob esta perspectiva, é precisamente a relevância máxima dos bens jurídicos tutelados, que devem ser resguardados por toda a sociedade internacional, e cuja violação, principalmente desde a $2^{\text {a }}$ Guerra Mundial, teria desencadeado uma "recusa da impunidade" (BAZELAIRE; CRETIN, 2004, p. 41-44).

Os tribunais penais internacionais, desde o Tribunal de Nuremberg até o Tribunal Penal Internacional, são evidências históricas desta afirmação, ainda que implícita, da jurisdição universal como instrumento de efetivação de direitos humanos, por meio da punição de fatos que consistem grave violação a direitos humanos, como o genocídio, os crimes contra a humanidade e os crimes de guerra. Nesse sentido, para além da dimensão institucional, essa tendência tem sido observada sob o aspecto normativo, haja vista a materialidade das Convenções de Genebra e do próprio Estatuto de Roma, por exemplo, como definidores de tais ilícitos internacionais.

A respeito, torna-se oportuno destacar o posicionamento de Antônio Augusto Cançado Trindade, em trecho de seu voto dissidente - e, portanto, contrário ao entendimento que foi adotado pela Corte Internacional de Justiça - no caso Congo v. Bélgica:

A consciência jurídica universal evoluiu de forma a não mais admitir obstáculos, no espaço ou no tempo, para a investigação e sanção a graves violações dos direitos humanos e do direito internacional humanitário. O exercício da jurisdição universal presta-se a superar os obstáculos existentes na dimensão do espaço. Além disso, serve para colmatar o fosso entre o tempo dos seres humanos e o tempo da justiça humana, de modo a superar obstáculos no tempo. É a gravidade das violações dos direitos humanos, dos crimes perpetrados, que não 
admite a extensão prolongada no tempo da impunidade dos autores, de modo a honrar a memória das vítimas fatais e buscando trazer alívio para os sobreviventes e seus familiares (CANÇADO TRINDADE, 2009, § 74-75)².

Nesse sentido, o exercício da jurisdição universal pode ser usado de modo a diminuir o abismo existente entre o breve lapso temporal da vida humana e o longo tempo da justiça humana. Isto é, pode ser uma maneira de restituir algum alívio às vítimas enquanto estão vivas, pois para elas o passar do tempo sem a punição dos violadores é doloroso, e por si só constitui a violação de outros direitos humanos, que passamos brevemente a analisar.

\section{DO DIREITO À COOPERAÇÃO JURÍDICA INTERNACIONAL}

A partir do desenvolvimento teórico e conceitual das seções supra, chega-se a uma temática deveras delicada, que envolve a possível existência de um direito à cooperação. Evitando-se a tentação de constatações absolutas, mas esvaziadas da responsabilidade com os mais diferentes casos que podem estar sob abrigo de um pleito cooperacional, afirmamos que a existência de um direito à cooperação jurídica internacional num pleito de cooperação é questão complexa, que deverá ser avaliada segundo peculiaridades do instituto em demanda e das circunstâncias que estejam envolvidas na medida em que se objetiva. Isso pois, a depender desses elementos, é possível a existência de contraposição entre direitos da vítima e do acusado/condenado, que deverão necessariamente ser ponderados.

De fato, a priori não é possível decidir o embate entre os direitos com base em seu titular, isto é, o fato de um indivíduo ser acusado ou condenado de graves violações de direitos humanos não necessariamente permite ou justifica a violação de seus direitos. Essa decisão deverá, pois, passar pelo exame dos direitos dos sujeitos envolvidos no pleito de cooperação, que deverão ser graduados segundo o bem jurídico tutelado e a potencial ofensa a esses bens jurídicos.

\subsection{O DIREITO À COOPERAÇÃO JURÍDICA SOB A ÓTICA DA VÍTIMA}

Sob a perspectiva das vítimas, a existência de determinados direitos humanos envolvidos no pleito cooperacional deve dar origem a um direito à cooperação. Tomemos o caso de pedidos de

\footnotetext{
${ }^{2}$ Tradução livre do original em língua inglesa: “The universal juridical conscience has evolved so as no longer to admit obstacles, in space or in time, to the investigation and sanction of grave violations of human rights and of international humanitarian law. The exercise of universal jurisdiction purports to overcome past obstacles in space. One is, furthermore, to bridge the gap between the time of human beings and the time of human justice, so as to overcome obstacles in time. It is the gravity of human rights violations, of the crimes perpetrated, that admits no prolonged extension in time of the impunity of the perpetrators, so as to honour the memory of the fatal victims and to bring relief to the surviving ones and their relatives".
}

Revista da Faculdade de Direito - UFPR, Curitiba, vol. 61, n. 3, set./dez. 2016, p. 277 - 297 
instrução criminal, de produção de provas e de extradição, que envolvem diretamente a concretização de certos direitos humanos das vítimas, bem como de seus familiares, previstos por diversas fontes do direito internacional.

A jurisprudência da Corte Interamericana é repetida no entendimento de que o direito à verdade e o direito à justiça são fundamentais para interromper o sofrimento constante das vítimas de graves violações de direitos humanos ${ }^{3,4}$, uma vez que a impunidade contribui para impedir a recuperação das vítimas, que tendem a continuar em um processo pós-traumático ${ }^{5}$.

O direito à verdade, a ser reconhecido e exercido em uma situação concreta, é também meio importante de reparação e corresponde a uma justa expectativa das vítimas, e que, portanto, deve ser satisfeita pelos Estados ${ }^{6}$. O direito à justiça, por sua vez, tange à obrigação dos Estados de combater a situação de impunidade, já que esta pode inclusive propiciar a repetição das violações de direitos humanos.

A Corte também destacou, em diversas oportunidades, que os familiares das vítimas de violações de direitos humanos podem ser, por sua vez, também vítimas. Isso pois a ausência de esclarecimento dos fatos violatórios e das responsabilidades correspondentes, mediante investigação e julgamento ${ }^{7}$, principalmente nos casos de vítimas fatais, pode desencadear violações à integridade psíquica e moral dos seus familiares ${ }^{8}$.

Inserido na obrigação de investigar, processar e punir os autores de violações de direitos humanos, está o dever dos Estados de organizar todo o aparato governamental e, em geral, todas as estruturas por meio das quais se manifesta o exercício do poder público, de maneira tal que sejam capazes de assegurar juridicamente o livre e pleno exercício dos direitos humanos ${ }^{9}$.

Ora, se os indivíduos são titulares do direito de exigir essa investigação, processo e punição no âmbito jurisdicional de um determinado Estado, não podem sofrer limitações a tal direito pelo fato de haver necessidade de realização de um ato processual por outro Estado, sob pena da frustração dos valores superiores da verdade e da justiça.

\footnotetext{
${ }^{3}$ Os casos citados são apenas a título exemplificativo, havendo muitos outros que reconhecem as mesmas questões.

${ }^{4}$ Corte IDH. Caso Barrios Altos Vs. Perú. Sentencia de 14 de marzo de 2001 (Fondo). Série C n. 75. § 47-48; Corte IDH. Caso Goiburú y otros vs. Paraguay. Fondo, Reparaciones y Costas. Sentencia de 22 de septiembre de 2006. Serie C No. 153.

${ }^{5}$ Corte IDH. Caso del Penal Miguel Castro Castro vs. Perú. Fondo, Reparaciones y Costas. Sentencia de 25 de noviembre de 2006. Serie C No. 160, §186.

${ }^{6}$ Corte IDH. Caso Goiburú y otros vs. Paraguay. Fondo, Reparaciones y Costas. Sentencia de 22 de septiembre de 2006. Serie C No. 164. § 96.

${ }^{7}$ Corte IDH. Caso Barrios Altos vs. Perú. Sentencia de 14 de marzo de 2001 (Fondo). Série C n. $75 . \S 48$.

${ }^{8}$ Corte IDH. Caso Goiburú y otros vs. Paraguay. Fondo, Reparaciones y Costas. Sentencia de 22 de septiembre de 2006. Serie C No. 153 § 96, 158.

${ }^{9}$ Corte IDH. Caso Velásquez Rodríguez. Mérito. § 166; Corte IDH. Caso Gomes Lund e outros vs. Brasil. ("Guerrilha do Araguaia”). Sentença de 24 de novembro de 2010. Série C, n. 219. § 85.
} 
A conclusão fica ainda mais evidente quando nos deparamos com graves violações primárias de direitos humanos que constituem crimes de lesa-humanidade, cuja proibição constitui norma de ius cogens, das quais decorre o dever dos Estados de não deixar que esses delitos fiquem impunes ${ }^{10}$. Para tanto, os Estados devem se utilizar de meios, instrumentos e mecanismos nacionais e internacionais para a persecução efetiva dessas condutas e a sanção dos autores, aí inclusos os pleitos cooperacionais $^{11}$.

De tal maneira, resta clara a existência de um direito à cooperação jurídica internacional, de titularidade das vítimas de violações de direitos humanos e de seus familiares, quando a cooperação é necessária à realização de atos de investigação, processo e punição dos autores. E, nas hipóteses em que está presente, esse direito encontra correlação com o dever dos Estados, sob uma dupla faceta: no dever dos Estados requerentes de darem início ao pleito cooperacional e no dever dos Estados requeridos de brindarem esforços com vistas à efetivação do pleito cooperacional e dos direitos que o fundamentam.

\subsection{O DIREITO À COOPERAÇÃO JURÍDICA SOB A ÓTICA DO ACUSADO/CONDENADO}

Não menos relevante, faz-se necessário também analisar a eventual existência de um direito à cooperação sob a ótica do acusado/condenado. Tomemos como contexto deste exame o pleito cooperacional para atos instrutórios a pedido da defesa e nos pedidos de cooperação para a transferência de sentenciados.

Pelo estudo das fontes primárias e secundárias, percebe-se que, de forma geral, os pedidos de assistência jurídica são de legitimidade de autoridades judiciárias (juízes ou Ministério Público) ou policiais, não gozando o acusado de capacidade para requerê-los. Nesse sentido, são comuns inclusive dispositivos nos acordos de cooperação que limitam esta possibilidade, a exemplo do Protocolo de San Luís ${ }^{12}$, que regula a cooperação penal entre os membros do Mercosul, e do Acordo Bilateral Brasil - Estados Unidos ${ }^{13}$.

\footnotetext{
${ }^{10}$ Corte IDH. Caso Almonacid Arellano y otros vs. Chile. Excepciones Preliminares, Fondo, Reparaciones y Costas. Sentencia de 26 de septiembre de 2006. Serie C No. 154, §99.

${ }^{11}$ Corte IDH. Caso del Penal Miguel Castro Castro vs. Perú. Fondo, Reparaciones y Costas. Sentencia de 25 de noviembre de 2006. Serie C No. 160, §404. Corte IDH. Caso La Cantuta Vs. Perú. Fondo, Reparaciones y Costas. Sentencia de 29 de noviembre de 2006. Serie C No. 162, § 159.

12 “Artigo 1.2. As disposições do presente Protocolo não conferem direitos aos particulares para a obtenção, supressão ou exclusão de provas, ou para se oporem ao cumprimento de uma solicitação de assistência.” O Protocolo foi promulgado por meio do Decreto n. 3.468, de 17 de maio de 2000. Cf. BRASIL, 2000.

${ }^{13}$ BRASIL. Decreto n. 3.810, de 2 de maio de 2001. “Artigo I.5. O presente Acordo destina-se tão-somente à assistência judiciária mútua entre as Partes. Seus dispositivos não darão direito a qualquer indivíduo de obter, suprimir ou excluir
} 
Esse tipo de dispositivo ofende princípios como a ampla defesa e o acesso aos meios e recursos a ela inerentes, bem como à paridade de armas entre as partes num processo, uma vez que o Ministério Público - com função “acusatória” em diversos sistemas jurídicos nacionais - tem ampla possibilidade de formular esses pedidos, instrumento em regra não disponíveis ao patrono da defesa.

Assim, quando houver indícios de que a produção de prova ou diligência extraterritorial seria essencial à observância de garantias processuais elementares, como a ampla defesa e o contraditório, entendemos existir um direito à cooperação, de titularidade do acusado. Esse direito, derivado do seu direito à defesa e ao devido processo legal, se traduzirá no dever da autoridade central brasileira de tramitar os pleitos cooperacionais da defesa, e no dever da autoridade estrangeira de recebê-los de forma indiscriminada independentemente da parte que os solicitou.

Diante da recusa a solicitações dessa ordem por parte das autoridades estrangeiras, inclusive com base nesses dispositivos dos acordos, é oportuna a sugestão de Vladimir Aras, para quem a solicitação de medida cooperacional de interesse da defesa deve ser submetida à autoridade central brasileira por intermédio da autoridade judiciária ou policial legitimada pelo Acordo (ARAS, 2010). Assim, o pedido será tramitado como prova ou diligência indicada pela defesa, mas de interesse da investigação ou da instrução processual, em respeito ainda ao princípio da verdade real.

A transferência de sentenciados, por sua vez, é medida de cooperação jurídica entre os Estados em matéria penal, que tem como objeto a transferência de pessoas condenadas em um país para cumprir no Estado de sua nacionalidade uma pena privativa de liberdade - aí abarcadas situações outras que não somente a prisão, a exemplo da vigilância, da liberdade condicional, antecipada ou vigiada, e da condenação condicional.

Segundo Ela Wiecko de Castilho, trata-se de "ato bilateral internacional discricionário, condicionado ao consentimento da pessoa transferida.” (CASTILHO, 2008) A discricionariedade, prevista expressamente nos acordos desse instituto, eliminaria a existência de um direito à transferência, mas subjaz o direito dos sentenciados de formular esses pedidos, e tê-los analisados pelo Estado.

Há, contudo, que se considerar o princípio da humanidade, que pugna pela minoração do sofrimento de quem se encontra encarcerado e distante de seu círculo familiar e cultural, bem como a finalidade da pena quando da análise desse pleito cooperacional pelos Estados.

qualquer prova ou impedir que uma solicitação seja atendida.” 


\section{DO DEVER DE COOPERAÇÃO DOS ESTADOS}

A observância dos direitos humanos dos indivíduos envolvidos no pleito cooperacional deve ser o filtro entre a existência do dever de cooperação por parte do Estado requerido em determinada situação ou a exigência de não cooperação, como enunciamos em breves linhas.

Naturalmente, a cogência das normas constantes de tratados internacionais ratificados por um determinado Estado é o elemento primordial que embasa a obrigatoriedade internacional e a existência de um dever internacional de cumprimento com as normas internacionais, não cabendo autorização para o descumprimento nem mesmo quando houver choque com o direito interno do respectivo Estado.

Não havendo, portanto, disputa sobre este dever quando o pleito cooperacional circula em uma relação entre jurisdições contornada por uma moldura convencional, desenhada pelas normas de um tratado internacional celebrado entre os respectivos Estados, esta seção se dedica às mais delicadas situações em que não existam tratados internacionais específicos sobre o tema entre os Estados em diálogo jurisdicional.

Reafirma-se, portanto, que o foco central dessa discussão acerca do dever de cooperar como inscrita no presente trabalho não abarca os casos em que há um tratado internacional expressamente estipulando uma obrigação específica de cooperação, mas em circunstâncias nas quais não haja obrigação convencional específica previamente pactuada (TROTTA; FERREIRA, 2010).

\subsection{A EXISTÊNCIA DE UM DEVER GERAL DE COOPERAÇÃO}

Após relevantes evoluções nas dimensões normativa, prescritiva e institucional da temática da proteção internacional dos direitos humanos, afirma-se na atualidade que a obrigação dos Estados face aos direitos humanos não se esgota na esfera negativa, de restrição à ação estatal, pela qual os Estados devem abster-se de cometer atos que violem esses direitos. Há também, e com maior relevo, a faceta positiva dessas obrigações, da qual decorre o dever dos Estados de promoção dos direitos humanos, e o consequente dever de investigar, processar e punir os responsáveis por sua violação.

Acreditamos, portanto, que desta faceta positiva também decorra o dever geral de cooperação por parte dos Estados, quando estejam envolvidos direitos humanos das vítimas, dos seus familiares, dos acusados e/ou dos condenados, conforme suprassuscitado.

Embora com frequência esteja previsto em tratados internacionais específicos, a existência desse dever em certas circunstâncias - tais como a violação de normas imperativas de direito internacional - prescinde da ratificação destes, pois se justifica pela própria natureza dos direitos 
envolvidos, e se fundamenta no costume internacional e em princípios basilares da ordem pública internacional.

Sobre essa questão, explicitou a Corte Interamericana de Direitos Humanos, no caso Catuta vs. Perú:

Dada a natureza e gravidade dos fatos, especialmente tratando-se de um contexto de violação sistemática dos direitos humanos, a necessidade de erradicar a impunidade se apresenta à comunidade internacional como um dever de cooperação interestatal para esta finalidade. $\mathrm{O}$ acesso à justiça é uma norma imperativa de direito internacional e, como tal, gera obrigações erga omnes para os Membros de tomar as medidas necessárias para não deixar impunes tais violações, quer exercendo a sua jurisdição para aplicar o seu direito interno e o Direito Internacional e para julgar e, se for o caso, punir os responsáveis por atos deste tipo, ou colaborando com outros Estados que o fazem ou tentam fazê-lo (grifo nosso) ${ }^{14}$.

Ademais, entendemos que o dever geral de cooperação se manifesta nos dois planos de concretização do pleito cooperacional, relativos à lógica ex parte principis e a lógica ex parte populi. Isto é, há uma faceta do dever geral de cooperação dos Estados, entre si e em face da sociedade internacional, que implicaria a obrigação de observância dos princípios caros à cooperação, a exemplo do aut dedere aut judicare, bem como das circunstâncias e limites eventualmente estabelecidos entre eles.

E há, por fim, um dever geral de cooperação dos Estados face aos indivíduos, diante da necessidade de concretização positiva de seus direitos no plano internacional.

\subsection{A EXIGÊNCIA DA NÃO COOPERAÇÃO}

Haja vista a complexidade da temática e a impropriedade de juízos maniqueístas nesta discussão, nem sempre a concessão do pleito cooperacional oferece a melhor resposta para o desafio da proteção internacional dos direitos humanos e da busca pelos ideais da justiça universal.

Isto é, o dever geral de cooperação deve ceder lugar à exigência de não cooperação, nas situações fático-jurídicas nas quais haja indícios significativos de que, uma vez concedida, a cooperação resultaria em violações de direitos humanos. Este é notadamente o caso dos pedidos de extradição para países nos quais o acusado/condenado estaria sujeito, por exemplo, à pena de morte,

\footnotetext{
${ }^{14}$ Tradução livre do original em língua espanhola: “Ante la naturaleza y gravedad de los hechos, más aún tratándose de un contexto de violación sistemática de derechos humanos, la necesidad de erradicar la impunidad se presenta ante la comunidad internacional como un deber de cooperación interestatal para estos efectos. El acceso a la justicia constituye una norma imperativa de Derecho Internacional y, como tal, genera obligaciones erga omnes para los Estados de adoptar las medidas que sean necesarias para no dejar en la impunidad esas violaciones, ya sea ejerciendo su jurisdicción para aplicar su derecho interno y el Derecho Internacional para juzgar y, en su caso, sancionar a los responsables de hechos de esa índole, o colaborando con otros Estados que lo hagan o procuren hacerlo”. Corte IDH. Caso La Cantuta Vs. Perú. Fondo, Reparaciones y Costas. Sentencia de 29 de noviembre de 2006. Serie C No. 162, § 160.
} 
ou a perseguições, ou, ainda, onde o sistema jurídico-institucional não seja capaz de garantir sua integridade e segurança.

De modo geral, é apropriada, na legislação interna, Constituição e nos tratados da matéria, a previsão de limites à cooperação, para resguardar os direitos humanos básicos das pessoas envolvidas (MORO, 2010). Ainda que não haja essa previsão, contudo, os Estados devem observar esses limites, sob pena inclusive de responsabilização pelas eventuais violações que sejam previsíveis à época do ato cooperacional.

É relevante destacar que a Corte Europeia de Direitos Humanos tem desenvolvido sua jurisprudência nesse sentido. A partir do caso Soering vs. Reino Unido vem sendo elaborada a teoria da "responsabilidade por ricochete", pela qual um Estado que extradite uma pessoa para um país no qual não haja garantia de não violação de seus direitos essenciais, como a vida e a integridade, pode vir a ser responsabilizado de forma indireta pelos delitos. No caso em questão, a Corte suscita uma possível violação do artigo 3 da Convenção, que traz a proibição de tortura:

Tal decisão pode levantar uma questão nos termos do artigo 3, portanto, envolver a responsabilidade desse Estado ao abrigo da Convenção, quando houver razões substanciais para crer que a pessoa, se liberada para o Estado requerente, correrá um risco real de ser submetida a tortura, ou a penas ou tratamentos desumanos ou degradantes. Para estabelecer essa responsabilidade não pode ser evitada a apreciação da situação do país de destino em termos dos requisitos do artigo 3. Não se trata de verificar ou provar a responsabilidade do país sob o direito internacional geral, nos termos da Convenção ou de outra forma. Na medida em que uma responsabilidade está ou pode estar inserida no campo da Convenção, esta seria a responsabilidade do Estado-membro da Convenção que autoriza a extradição, por tratar-se de um ato que tem como consequência direta a exposição a qualquer um dos maus tratos proibidos $^{15}$.

É certo que essa avaliação exige uma análise criteriosa, sob pena de enfraquecer a cooperação jurídica internacional e de criar espaços de impunidade. Não sem motivo, essa avaliação tem sido realizada com cautela pela Corte, cujos precedentes delineiam também a obrigação dos Estados de recusarem a cooperação quando ficar evidenciado que a condenação é fruto de uma "flagrante denegação de justiça”16.

Por fim, cumpre destacar que a própria internacionalização da temática dos direitos humanos

\footnotetext{
${ }^{15}$ Tradução livre do original em língua francesa: "pareille décision peut soulever un problème au regard de l'article 3 (art. 3), donc engager la responsabilité d'un État contractant au titre de la Convention, lorsqu'il y a des motifs sérieux et avérés de croire que l'intéressé, si on le livre à l'État requérant, y courra un risque réel d'être soumis à la torture, ou à des peines ou traitements inhumains ou dégradants. Pour établir une telle responsabilité, on ne peut éviter d'apprécier la situation dans le pays de destination à l'aune des exigences de l'article 3 (art. 3). Il ne s'agit pas pour autant de constater ou prouver la responsabilité de ce pays en droit international général, en vertu de la Convention ou autrement. Dans la mesure où une responsabilité se trouve ou peut se trouver engagée sur le terrain de la Convention, c'est celle de l'État contractant qui extrade, à raison d'un acte qui a pour résultat direct d'exposer quelqu'un à des mauvais traitements prohibés”. Corte EDH. 7 juillet 1989, Soering c. Royaume Uni, n. 14 038/88.

${ }^{16}$ Corte EDH. 26 juin 1992, Drozd et Janousek c. France et Espagne, n. 12 747/87.
} 
trouxe como consequência a concordância com a responsabilização internacional dos Estados infratores (RAMOS, 2005). Assim, seguindo o raciocínio deste trabalho, é possível arguir que existe a possibilidade de responsabilização, no direito internacional, dos Estados que descumprirem seu dever de cooperação, por razões outras que não o resguardo de direitos humanos essenciais, esteja esta denegação calcada em ato executivo, legislativo ou judiciário. Naturalmente, tendo em conta os diversos desafios estruturais e procedimentais da ordem jurídica internacional, tal responsabilização - possível em tese e coerente com o tipo de raciocínio jurídico supramencionado - demandaria um tribunal internacional competente e disposto a alcançar tal interpretação, embora os elementos normativos e hermenêuticos já estejam presentes na ordem jurídica internacional.

\section{CONSIDERAÇÕES FINAIS}

Conforme se observou ao longo deste trabalho, a mudança do paradigma soberanista da jurisdição estatal, com vistas ao desenvolvimento de um ambiente internacional de cooperação entre os sujeitos da sociedade internacional é premente. Embora tal evolução não seja isenta de desafios, estes devem ser enfrentados pelos diferentes Estados, tendo em conta principalmente a perspectiva dos direitos humanos dos sujeitos envolvidos nos pleitos cooperacionais.

O Brasil não está alheio a esta tendência, e tem buscado desenvolver sua capacidade de participação nesta nova realidade, que exige uma reformulação do processo tradicional e uma abertura consciente e responsável aos pedidos na cooperação jurídica internacional passiva, bem como uma proatividade no tocante aos pedidos de cooperação jurídica internacional ativa ${ }^{17}$.

O Novo Código de Processo Civil, já em vigor no País, demonstra essa tendência, ao prever - em capítulo denominado "Da Cooperação Jurídica Internacional” - instrumentos e princípios norteadores da cooperação sob a perspectiva do Judiciário nacional. Merece destaque nesse diploma o artigo 26, por mencionar princípios norteadores, institutos a serem respeitados nos pleitos cooperacionais $^{18}$. Embora trate-se de um potencial dispositivo a guiar principalmente os pleitos de

\footnotetext{
${ }^{17}$ O Manual de Cooperação Jurídica Internacional, elaborado pelo Departamento de Recuperaçaõ de Ativos e Cooperaçaõ Jurídica Internacional, como meio de conscientização nesta temática, explicita a relevância crescente da participação do Brasil em ambos os polos da cooperação jurídica internacional: "[...] Considerando-se as estatísticas produzidas pelo Departamento de Recuperaçaõ de Ativos e Cooperaçaõ Jurídica Internacional (DRCI), verifica-se que de 2004 a 2010, houve incremento de mais de $40 \%$ no número de pedidos de cooperaçã̃ anuais tramitados no Ministério da Justiça. Saiuse de um patamar de algo em torno de 2800 pedidos em 2004 para mais de 4000 em 2010. [...] Outro dado relevante é a prevalência do Brasil como solicitante de cooperaçaõ. Do total de pedidos de cooperaçaõ jurídica tramitados em 2010 e 2011, mais de 85\% saíram do país se dirigindo a uma autoridade estrangeira. [...]” BRASIL, 2012, p. 18.

18 “Art. 26. A cooperação jurídica internacional será regida por tratado do qual o Brasil seja parte e observará: I - o respeito às garantias do devido processo legal no Estado requerente; II - a igualdade de tratamento entre nacionais e estrangeiros, residentes ou naõ no Brasil, em relaçã̃ ao acesso à justiça e à tramitaçaõ dos processos, assegurando-se assistência judiciária aos necessitados; III - a publicidade processual, exceto nas hipóteses de sigilo previstas na legislaçaõ brasileira
} 
cooperação em matéria cível, sua potencial relevância no processo penal não pode ser descartada, tendo em vista a interpretação analógica permitida pelo artigo $3^{\circ}$ do Código de Processo Penal, uma vez que o dispositivo em comento tem natureza geral e principiológica. Com base em tal dispositivo, é possível desenvolver parâmetros para a observância do direito à cooperação e do dever de cooperação pelo Estado brasileiro.

O respeito ao direito à cooperação jurídica internacional, em certas situações, e ao dever geral, mas não absoluto - de cooperação, é essencial à construção de uma verdadeira comunidade internacional, na qual coexistam as peculiaridades políticas e jurídicas dos Estados, equilibradas mediante o elemento harmonizador de uma consciência jurídica universal. A visível evolução dos institutos cooperativos, acompanhada da própria evolução das instituições do direito internacional, indica-nos que já estamos trilhando este caminho, partindo de um soberanismo voluntarista baseado na discricionariedade estatal, em direção ao reconhecimento da imperatividade de valores como a justiça universal e o respeito aos direitos humanos.

\section{REFERÊNCIAS}

ABADE, Denise Neves. Direitos fundamentais na cooperação jurídica internacional: extradição, assistência mútua, execução de sentença estrangeira e transferência de presos. São Paulo: Saraiva, 2013.

ABBOTT, Kenneth W.; SNIDAL, Duncan. Pathways to International Cooperation. In: BENVENISTI, Eyal; HIRCH, Morshe (Org.). The Impact of International Law on International Cooperation. New York: Cambridge University Press, 2004. p. 50-84.

ANISTIA INTERNACIONAL. Universal Jurisdiction: The Duty of States to Enact and Implement Legislation. London: Amnesty International, 2001.

ARAS, Vladimir. O papel da autoridade central nos acordos de cooperação penal internacional. In: BALTAZAR JR. José Paulo; LIMA, Luciano Flores. Cooperação jurídica internacional em matéria penal. Porto Alegre: Verbo Juridico, 2010, p. 59-94.

ARAUJO, Nadia de et al. Importância da Cooperação Jurídica Internacional e seu Desenvolvimento. In: ARAUJO, Nadia de (Coord.). Cooperação jurídica internacional no Superior Tribunal de Justiça - Comentários à Resolução nº 9/2005. Rio de Janeiro: Renovar, 2010, p. 1-17.

BAZELAIRE, Jean-Paul; CRETIN, Thierry. A justiça penal internacional: sua evolução, seu futuro - de Nuremberg a Haia. Barueri: Manole, 2004.

BRASIL. Decreto n. 3.468, de 17 de maio de 2000. Promulga o Protocolo de Assistência Jurídica

ou na do Estado requerente; IV - a existência de autoridade central para recepçã̃ e transmissaõ dos pedidos de cooperaçaõ; V - a espontaneidade na transmissaõ de informaçoẽs a autoridades estrangeiras.”

Revista da Faculdade de Direito - UFPR, Curitiba, vol. 61, n. 3, set./dez. 2016, p. 277 - 297 
Mútua em Assuntos Penais, assinado em San Luis, República Argentina, em 25 de junho de 1996, entre os Governos da República Federativa do Brasil, da República Argentina, da República do Paraguai e da República Oriental do Uruguai. Brasília, DF, Diário Oficial da União, 18 maio 2000. Disponível em: <https://goo.gl/OHnRdx>. Acesso em: 10 dez. 2014.

. Decreto n. 3.810, de 2 de maio de 2001. Promulga o Acordo de Assistência Judiciária em Matéria Penal entre o Governo da República Federativa do Brasil e o Governo dos Estados Unidos da América, celebrado em Brasília, em 14 de outubro de 1997, corrigido em sua versão em português, por troca de Notas, em 15 de fevereiro de 2001. Brasília, DF, Diário Oficial da União, 3 maio 2001. Disponível em: <https://goo.gl/TNNXCT>. Acesso em: 10 dez. 2014.

Secretaria Nacional de Justiça. Departamento de Recuperaçã̃ de Ativos e Cooperaçaõ Jurídica Internacional. Manual de cooperaçaõ juridica internacional e recuperaçaõ de ativos: cooperaçaõ em matéria penal. 2. ed. Brasília: Ministério da Justiça, 2012.

BROWNLIE, Ian. Principles of International Law. 6. ed. Oxford: Oxford University Press, 2003.

CANÇADO TRINDADE, Antônio Augusto. A humanização do direito internacional. Belo Horizonte: Del Rey, 2008.

Dissenting Opinion. Question Related to the Obligation to Prosecute or Extradite. Belgium v. Senegal. Request for the Indication of Provisional Measures, 28 May 2009.

CASTILHO, Ela Wiecko V. de. Cooperação internacional na execução da pena: a transferência de presos. In: Revista Brasileira de Ciências Criminais, v. 71, 2008.

CORTE EUROPEIA DE DIREITOS HUMANOS. 26 juin 1992. Drozd et Janousek c. France et Espagne, n. 12 747/87.

7 juillet 1989. Soering c. Royaume Uni, n. 14 038/88.

CORTE INTERAMERICANA DE DIREITOS HUMANOS. Caso Almonacid Arellano y otros vs. Chile. Excepciones Preliminares, Fondo, Reparaciones y Costas. Sentencia de 26 de septiembre de 2006. Serie C No. 154, §99.

. Caso Barrios Altos vs. Perú. Sentencia de 14 de marzo de 2001 (Fondo). Série C n. 75.

. Caso del Penal Miguel Castro Castro vs. Perú. Fondo, Reparaciones y Costas. Sentencia de 25 de noviembre de 2006. Serie C No. 160.

Caso Goiburú y otros vs. Paraguay. Fondo, Reparaciones y Costas. Sentencia de 22 de septiembre de 2006. Serie C No. 153.

Caso Gomes Lund e outros vs. Brasil. (“Guerrilha do Araguaia”). Sentença de 24 de novembro de 2010. Série C, n. 219.

. Caso La Cantuta vs. Perú. Fondo, Reparaciones y Costas. Sentencia de 29 de noviembre de 2006. Serie C No. 162, § 159. 
No. 4.

. Caso Velásquez Rodríguez vs. Honduras. Fondo. Sentencia de 29 de julio de 1988. Serie C

HAWKINS, Darren. Universal Jurisdiction for Human Rights: From Legal Principle to Limited Reality. In: Global Governance, v. 9, p. 347-365, 2003.

LOULA, Maria Rosa Guimarães. Auxílio direto: novo instrumento de cooperação jurídica em matéria civil. Belo Horizonte: Fórum, 2010.

LOWE, Vaughan. Jurisdiction. In: EVANS, Malcom (Ed.). International Law. New York: Oxford University Press, p. 329-355, 2006.

MENEZES, Wagner. Direito internacional na América Latina. Curitiba: Juruá, 2007.

. Ordem Global e transnormatividade. Ijuí: Unijuí, 2005.

MORO, Sérgio Fernando. Cooperação jurídica internacional em casos criminais: considerações gerais. In: BALTAZAR JR., José Paulo; LIMA, Luciano Flores de. Cooperação jurídica internacional em matéria penal. Porto Alegre: Verbo Jurídico, 2010, p. 15-58.

OTAVIO, Rodrigo. Direito internacional privado. Parte geral. Rio de Janeiro: Ed. Freitas Bastos, 1942.

PETRUS, Christian Herrera. La obtención internacional de pruebas, asistencia jurisdicional en Europa. Bolonia: Publicaciones del Real Colégio de Espana, 2005.

PIOVESAN, Flávia. Direitos humanos e justiça internacional. São Paulo: Saraiva, 2010.

RAMOS, André de Carvalho. Estrutura da cooperação jurídica internacional e o novo direito internacional privado. In: CHOUKR, Fauzi Hassan; PAGLIARINI, Alexandre Coutinho. Cooperação jurídica internacional. Belo Horizonte: Ed. Fórum, 2014. p. 163-180.

Responsabilidade Internacional do Estado por Violação de Direitos Humanos. In: Revista CEJ. Brasília, n. 29, p. 53-63, abr./jun. 2005.

SLAUGHTER, Anne-Marie. Sovereignty and Power in a Networked World Order. In: Standford Journal of International Law, v. 40, p. 283-327, 2004.

TROTTA, Sandro Brescovit; FERREIRA, Luciano Vaz. Da obrigatoriedade de cooperar e os recursos cabíveis em casos de descumprimento de tratado internacional. In: BALTAZAR JR., José Paulo; LIMA, Luciano Flores de. Cooperação jurídica internacional em matéria penal. Porto Alegre: Verbo Jurídico, 2010. p. 95-122.

\section{DIMENSIONS OF INTERNATIONAL JUDICIAL COOPERATION: FROM THE RIGHT OF COOPERATION TO THE DUTY TO COOPERATE}




\begin{abstract}
Given the intense flow of people and human activities that transit beyond the porous borders of States, there is a clear failure of the State jurisdiction empire and an urgent need to develop a new paradigm for understanding the relationship between the States and the subject, acts and claims under their jurisdiction. International judicial cooperation, in its various instruments, is at the heart of this new paradigm, in a context of reinterpretation of sovereignty and jurisdiction, and towards the universal jurisdiction as an international value. This paper analyzes the different dimensions of international judicial cooperation, with special focus on the reflection about the existence of a right of cooperation and a duty to cooperate, in the light of materializing human rights of persons involved. With this intent, the paper is developed through a systemic analysis of doctrine and international jurisprudence in this regard.
\end{abstract}

\title{
KEYWORDS
}

International judicial cooperation. Right of cooperation. Duty to cooperate. Principle of universal justice. Human rights. 